Indexaciones: Repositorio de Revistas UCR, DIALNET, Latindex, REDALYC Directorio y recolector de recursos digitales del Ministerio de Cultura de España, Directory of Open Access Journals. Diálogos Revista Electrónica de Historia ISSN 1409-469X. Número especial 2008. Dirección web: http://historia.fcs.ucr.ac.cr/dialogos.htm

\section{Características geohistóricas de la ocupación del espacio en la vertiente occidental de la Cordillera de la Costa, Provincia de Talca y Cauquenes, Región del Maule, Chile.}

Ana María Cabello Quiñones*

Geografía y Gestión Ambiental, Directora Carrera Ped. Historia, Geografía y Cs. Sociales, Universidad Autónoma de Chile, Sede Talca. Correo electrónico: acabelloq@talca.uas.cl 


\title{
Características geohistóricas de la ocupación del espacio en la vertiente occidental de la Cordillera de la Costa, Provincia de Talca y Cauquenes, Región del Maule, Chile.
}

\author{
Ana María Cabello Quiñones *
}

\section{Introducción}

En cada época el uso del espacio se circunscribe a las necesidades de la comunidad, que son reflejo del nivel político, económico y cultural que mantienen en el período, modificándose acorde a como varían estos elementos de la sociedad y que representan los hitos de uso del suelo y el cambio ambiental que se produce en el espacio.

La sociedad cambia y los seres humanos también se transforman a través del tiempo y con ello sus necesidades, intereses y actividades económicas, las que generan una dinámica geoambiental propia del área.

Este fenómeno de cambio en el uso del espacio ha definido a la Cordillera de la Costa en la Región del Maule en rexistacia, con una modificación profunda e irreversible del paisaje, hecho que se ha mantenido desde los inicios del siglo 20 y que en el siglo 21 se manifiesta en un desequilibrio del geosistema global.

\section{Descripción del área}

Este trabajo de investigación se desarrolla en el área correspondiente a la vertiente occidental de la cordillera costera de la Región del Maule, zona central de Chile perteneciente a las Provincias de Talca y Cauquenes, específicamente en las comunas de Constitución, Empedrado y Chanco; se localiza a $\operatorname{los} 35^{\circ} 5^{\prime}$ y $36^{\circ}$ de latitud sur y a los $72^{\circ} 10^{\prime}$ con $72^{\circ} 45^{\prime}$ de longitud oeste.

La zona es de antiguo poblamiento, uno de los más añosos de la costa de la región, en la que existen centros poblados de larga data, entre los que se pueden señalar Constitución, Chanco, Pahuil, 
Loanco, que se encuentran entre los grupos primitivos que poblaron la costa, aprovechando los recursos naturales caracterizándose por su carácter recolector. El hallazgo de vestigios arqueológicos como conchales, cerámicas, cavernas y otros, dan cuenta de la relevancia de estos sitios en el pasado, los que constituirán los centros poblados del siglo XVIII y que en la actualidad representan los pueblos radicados en la Cordillera de la Costa.

El aumento de la población a partir de la década del 70, indica la importancia que ha adquirido el área en estudio y las profundas transformaciones del espacio, producto de las actividades agrícolas y silvícolas que se han desarrollado desde el siglo XIX.

\section{El medio ambiente natural y su influencia en la ocupación del espacio.}

Las características geográficas naturales del espacio vertiente occidental de la Cordillera de la Costa, Región del Maule, han influído en su ocupación humana a lo largo del tiempo. Sin caer en el determinismo geográfico, los factores de relieve, clima, hidrografía, flora y fauna que caracterizan el paisaje zonal, han sido significativos en la localización de los asentamientos humanos y del uso del suelo.

El Clima, de acuerdo a la clasificación genética de los climas chilenos de Peña y Romero (1977), la franja de estudio se denomina "Clima de período seco estival", cuyo carácter alternado que presentan las características de la circulación, determina una evolución anual sin predominio neto de formas sinópticas en términos de frecuencia. Sin embargo se observa en términos generales que las condiciones ciclonales son ligeramente más importantes entre mayo y septiembre, siendo superadas por las condiciones no específicas el resto del año. Los vientos dominantes son los provenientes del sur y sureste, observándose flujos dominantes estivales del sur, debido a la mayor intensidad de la "Alta del Pacífico Sudoriental"; en invierno en cambio, existe una masa 
de aire proveniente del oeste, que coincide con el traslado de las depresiones hacia el norte. El área observada presenta su estación seca en verano, con una gran radiación solar, solamente alterada en el litoral por cambios esporádicos de las condiciones oceanográficas y mal tiempo; el invierno es más húmedo y lluvioso, presenta temperaturas estables y una escasa oscilación térmica diaria, manteniendo abundantes nublados y brisas muy fuertes.

Las áreas con más días frescos y nublados corresponden a Faro Carranza y Bahía de Chanco, ambos sectores de topografía escarpada, accidentada, expuestos a las masas de aire y con playas amplias sin protección. Pellines y Loanco son sectores más protegidos, sin embargo también presentan días nublados, vientos húmedos y precipitaciones invernales significativas.

La morfología del lugar, afecta indudablemente la circulación zonal ya que los sistemas geomorfológicos se disponen en forma latitudinal, como lo son los cordones cordilleranos costeros, que se desplazan hacia el interior del continente, formando valles encajonados, de fuerte pendiente y la formación de cuencas intermontanas de condiciones climáticas locales, permitiendo que las masas de aire ingresen desde la costa y choquen con la barrera de relieve costero, pasando hacia el interior como masa de aire seca, hecho que aumenta la falta de agua en estos sectores denominados de "secano"; la cuenca de Empedrado, localizada en el borde oriental de la Cordillera de la Costa, representa un subsistema de cuenca granítica marginal típica del fenómeno mencionado.

Las precipitaciones irregulares de la zona, generan incertidumbre climática que desfavorece el uso agrícola de los suelos que carecen de riego pero que sin embargo es óptimo para el uso forestal ya que las masas de aire provenientes del Océano Pacífico posibilitan humedad permanente en el ambiente.

La Cordillera Costera a esta latitud, presenta un relieve ondulado, cuya altura no sobrepasa los 
500 metros, a excepción del cerro Name que posee 810 metros, siendo el hito de mayor altura en esta región; constituye un biombo climático de tipo longitudinal, localizado en toda la vertiente occidental de esta unidad orográfica en estudio.

Los procesos morfogenéticos de mayor trascendencia corresponden a la erosión de los suelos de pendiente fuerte, lavado superficial y lixiviación de extensas áreas desprotegidas y acumulación detrítica en tierras bajas.

La otras unidades de relieve del área de estudio las conforman planicies litorales y fluvio marinas de la costa, ocupadas actualmente por dunas y paleodunas ubicadas en la línea litoral bajo los 400 metros. de altura.

Existen características geológicas estructurales que le otorgan individualidad a esta unidad geomorfológica: la Cordillera de la Costa y borde costero asociadas a fallas tectónicas y planicies de abrasión marina, quedando además de manifiesto la gran disección del río Maule en la desembocadura, que es el río de da nombre a la región y que además presenta una morfología de sedimentos fluviovolcánicos, generando una zona amplia de embancamiento y barra de arenas. Los suelos de esta zona están determinados por la incidencia de una estación seca prolongada y una humedad invernal breve. El general el clima permite el desarrollo de molisoles, caracterizados por una fuerte intemperización y lixiviación, los que se presentan sobre la Cordillera de la Costa; hacia el interior, los suelos son alfisoles de mayor evolución, en donde alcanza una gran importancia la intemperización química y el ciclo orgánico: corresponden al área específica de Constitución-Cauquenes y Empedrado respectivamente.

Es común encontrar material parental (roca madre) in situ aflorando a la superficie, producto de la degradación del suelo por el uso excesivo y la construcción de caminos de acceso que posibilitan la conectividad del área y el traslado de los productos agrícolas y forestales para 
comercialización.

La vegetación del área estudiada corresponde a la Ecoregión de los bosques laurifoliados esclerófilos; este es el bosque más típico y representativo de la Cordillera de la Costa de la Región del Maule, especialmente en la vertiente occidental, de hoja perenne, que adquiere una mayor altura según sea la cantidad de precipitación recibida. Es la Provincia de Cauquenes la que posee la mayor superficie de bosque nativo de "ruiles" un tipo de nothofagus que se encuentra bajo régimen de Reserva Protegida (CONAF, Corporación Nacional Forestal); en cambio la Provincia de Constitución ha visto desaparecer su vegetación arbórea histórica de Roble pellín, Avellanos, Quillay y otros, bajo el impacto antrópico desde el siglo 18, observando actualmente sólo la presencia de renovales, los que crecen en forma dispersa con mucha dificultad por la presencia asfixiante y colonizadora de las especies exóticas introducidas para fines maderables y de celulosa, como el Pinus radiata y Eucaliptos globulus.

La vegetación nativa ha sido explotada al límite de la extinción, por las actividades económicas iniciadas en el siglo 18, en el que la zona costera de Constitución, denominada Nueva Bilbao en esa época, constituía el gran puerto de la región, que recepcionaba la producción cerealera del interior y la exportaba por esta vía; el impacto sobre la vegetación fue precisamente el requerir madera noble impermeable para la construcción de "faluchos maulinos", embarcaciones típicas de la zona, de amplia comercialización hasta el siglo 20, para los cuales era imprescindible el uso de roble pellín que aseguraba calidad y precios elevados. Por otro lado, el desbroce del monte para tierras de cultivos de cereales y leguminosas, impidió la regeneración natural del bosque, transformando el área hacia el siglo 20, período en que se decidió la reforestación de la Cordillera de la Costa con especies de crecimiento rápido y comercializable.

Sin embargo, en el mismo siglo 20, la sedimentación excesiva acarreada por el Río Maule provocó 
la formación de una barrera de arenas en su desembocadura en Constitución, que inhabilitó la cualidad navegable del río y con ellos el transporte de productos desde el interior. La ciudad de Constitución pierde la importancia portuaria que poseía en el siglo 19, produciéndose una acentuación de la actividad agrícola en toda la Cordillera costera e incremento de la pesca y marisqueo aprovechando los recursos ictícolas del litoral, que continúan caracterizando al borde costero del Maule.

Sólo en quebradas más húmedas, se puede encontrar renuevos de especies higrófitas como canelo, avellano, quillay, roble y coigüe, boldo y litre, específicamente en la zona denominada "la montaña" en las comunas de Pelluhue y Curanipe, pero cada vez en menor proporción; cabe resaltar que estas pequeñas unidades son impactadas por la población lugareña, que obtiene leña de subsistencia de los matorrales así como setas comestibles, frutas silvestres y extracción de hierbas medicinales, que se comercializan en los centros poblados cercanos.

El caso más representativo de la pérdida de cobertura vegetal natural es el de la Comuna de Empedrado, con una reforestación que marca una transformación fitogeográfica: ha desaparecido el tapiz nativo y se ha reemplazado por la especie Pinus radiata introducida, que implica beneficios económicos importantes para la Región del Maule, que posee la industria de Celulosa Arauco-Constitución, instalada en el borde costero, desde el año 1971. La comuna por tanto, ha sufrido una rexistacia del paisaje o modificación absoluta sin retroceso, siendo la actividad forestal-silvícola la única existente en la actualidad y que ocupa el 100\% del uso del suelo y de la mano de obra económicamente activa del sector.

Las comunas más impactadas en el cambio de uso del suelo corresponden a Constitución y Empedrado, ambas pertenecientes a la Provincia de Talca; degradadas, pero en menor proporción las áreas de Loanco y Chanco de la Provincia de Cauquenes, todas ellas localizadas en la vertiente 
occidental de la Cordillera de la Costa.

En la Comuna de Constitución, el mayor cambio de uso del espacio se ha generado por la pérdida de las características naturales del paisaje local, que obligó a la radicación de la principal industria pesada de la Región: la Celulosa Arauco- Constitución. Este fenómeno modificó la historia de esta área de antiguo poblamiento que data de 1794, año de fundación por orden del Gobernador Ambrosio O"Higgins, constituyendo las primeras Haciendas como la de Carrizal en que se instaló el primer Taller para fabricar telas, siendo la primera industria del corregimiento del Maule. Otra empresa importante la constituyó el establecimiento de un astillero en la ribera norte del río Maule, en el que se construyeron navíos para particulares, iniciándose así el comercio marítimo por las costas del Pacífico de la Región del Maule.

A fines del siglo17, el Puerto de Nueva Bilbao es famoso por sus construcciones hechas en madera de la zona, "roble maulino"; se denominaron faluchos maulinos y se convirtieron en la primera actividad económica cuya materia prima se localiza en las inmediaciones del puerto: los troncos se traían desde el interior de la Cordillera de la Costa, de mayor edad y más diámetro y longitud, provocando con ello un desequilibrio sostenido del paisaje natural.

Durante todo el siglo 18 y 19 se alternaron las actividades de astilleros, explotación del bosque nativo en la ribera del curso medio e inferior del río Maule, junto al uso agrícola-ganadero que se inicia a inicios del siglo 19, produciéndose una ocupación intensa de la ribera norte y sur del Maule, desde las localidades de Putú a Faro Carranza y Chanco por el borde costero.

Se tala la escasa vegetación que no había sido utilizada por los astilleros, se rotura el suelo y se cultiva con trigo y leguminosas preferentemente; también la cría de ganado bovino aprovechando los excelentes pastos salinos costeros.

El advenimiento del siglo 20 encuentra un nuevo paisaje geográfico, la vegetación nativa ha sido 
prácticamente exterminada y se ha reemplazado en forma espontánea por un matorral esclerófilo de escasa importancia, con la asociación de un tapiz herbáceo denso en aquellos cordones costeros cercanos a la influencia marítima. Del bosque maulino que impresionó al Conquistador Español, sólo quedan algunas muestras al interior de las quebradas y en sectores de mayor altura.

En tres siglos, se logró un completo deterioro de la vegetación y el suelo de la Cordillera de la Costa; la tala indiscriminada de cobertura natural dejó expuesto el suelo, que sufre procesos de intemperización con efectos de erosión grave y severa (IREN-CORFO), grietas profundas y pérdidas del horizonte orgánico, cuyo geosistema se encuentra en desequilibrio o inestabilidad crónica, debido a fuerzas fundamentalmente antrópicas que imposibilita la vuelta al estadio normal climático del paisaje.

En el año 1976 de instala la industria Celulosa -Constitución (CELCO) en la planicie litoral, al sur de la desembocadura del río Maule. La compra de los predios aledaños de la cordillera costera cercana pasan a ser plantados por la especie Pinus insigne y radiata, junto con la tala de renovales nativos desde la década del 60, de tal forma que a la radicación de la planta ya existe materia prima para su abastecimiento. A la década del 90, ya se habían reforestado todos los cordones, incluyendo las áreas intermontanas, como por ejemplo en la que se localiza Empedrado, comuna que pasa de un estadio de renovales nativos a la forestación extrema, incluyendo la venta de parcelas agrícolas, obteniendo la empresa Celulosa la expansión máxima de plantíos en la Cordillera de la Costa de la Región del Maule, con una superficie plantada que la deja en el $2^{\circ}$ lugar de mayor producción del país.

Más al sur, desde Pellines a Loanco, la actividad forestal se ve alternada con la incipiente industria artesanal de pesca y marisqueo, que se ha fortalecido desde la década del 80: rudimentaria, pero durante todo el año, ha ido poblando el borde costero en forma paulatina, generando centros 
mejorado la calidad de vida del lugareño y lugareña, ya que es un uso del espacio modernizador, en el que la mujer ha sido incorporada masivamente, transformando la población económicamente activa del centro poblado y de la provincia de Cauquenes en general.

La declaración de Ciudad Patrimonial otorgado a Chanco desde el año 2000, le ha permitido un uso del espacio diferente basado en turismo ecológico, en algunas de las haciendas localizadas cercanas al centro poblado, siendo la Hacienda Bonifacio la mejor implementada, con un nivel de tres estrellas otorgados por el Servicio Nacional de Turismo (SERNATUR); esta actividad utiliza la infraestructura que otrora se ocupara en la crianza de ganado y lechería, ofreciendo al público un turismo campestre de cabalgatas y paseos por el litoral cercano, manteniendo el uso del suelo tradicional en gran parte del predio.

Es este centro poblado sin duda, el que mejor conserva el uso del espacio que caracterizó a la vertiente occidental de la Cordillera de la Costa de la Región del Maule en el pasado, constituyendo un área típica con un sello de identidad patrimonial que la comunidad regional valora enormemente.

\section{Conclusiones}

1.- En las áreas Constitución y Empedrado existen cambios irreversibles en el uso del espacio, generados por la actividad económica intensa cerealera y astillera realizada por el hombre en los siglos 17 al 19, que caracteriza a la zona por una franca rexistacia.

2.- La comuna de Chanco es sin duda la que conserva el uso del espacio tradicional que caracterizó a la vertiente occidental de la Cordillera de la Costa, alternando en la actualidad con un uso de los espacios en pro del turismo ecológico y de aventura, aprovechando las infraestructuras de haciendas existentes en la zona.

3.- El uso del espacio silvícola predomina en la unidad vertiente occidental de la Cordillera 


\section{OI 9० CONGRESO

de la Costa a partir del siglo 20, reemplazando el uso tradicional cerealero y de leguminosas, fundamentalmente por la pérdida de calidad del suelo.

4.- El bosque nativo de roble maulino ha desaparecido en toda la zona de estudio, producto de la sobreexplotación de las especies desde el siglo 17, fenómeno que conduce a la reforestación masiva con especies foráneas de Pino insigne y Eucaliptos globulus, que han transformado la fisonomía del paisaje costero de la Región del Maule. 
Indexaciones: Repositorio de Revistas UCR, DIALNET, Latindex, REDALYC Directorio y recolector de recursos digitales del Ministerio de Cultura de España, Directory of Open Access Journals.

Diálogos Revista Electrónica de Historia ISSN 1409-469X. Número especial 2008. Dirección web: http://historia.fcs.ucr.ac.cr/dialogos.htm

\section{Bibliografía}

1.- Adriana Hoffmann, La Vegetación de Chile, (Santiago de Chile, Editorial Universitaria, 1980)

2.-Hugo Romero, Los Climas de Chile, (Santiago de Chile, Colección Instituto Geográfico Militar, 1985).

3.-Adriano Rovira, Los Suelos de Chile, (Santiago de Chile, Colección Instituto Geográfico Militar, 1985).

4.- Corporación de Fomento, CORFO, Geografía Económica de Chile (Santiago de Chile, Texto Refundido, Editorial Universitaria, 1965).

5.-Dídima Olave, “La degradación de la vegetación nativa de la VII Región”, Revista Geografía e Historia, IPGH (México), (1985). 